\title{
SEM and EDS Study in Bidirectional Fabrics of Composites Materials for Aeronautical Applications
}

EE Vera-Cárdenas ${ }^{1 *}$, JC Mendoza Mendoza ${ }^{1}$, AI Martínez Pérez ${ }^{2}$, EO Ávila Dávila ${ }^{1}$, S LedesmaLedesma $^{3}$ and M Moreno-Rios ${ }^{1}$

1. Tecnológico Nacional de México/I.T.Pachuca, Carretera México-Pachuca Km. 87.5, Colonia Venta Prieta, C.P. 42080 Pachuca de Soto, Hgo., México.

2. Departamento de Ingeniería Mecánica Automotriz, Universidad Politécnica de Pachuca, Carretera Pachuca-Ciudad Sahagún km 20, Ex-Hacienda de Santa Bárbara, C.P. 43830 Zempoala, Hgo., México.

3. Centro de Ingeniería y Desarrollo Industrial, Playa Pie de la cuesta 702, Desarrollo San Pablo, Querétaro, Qro.

*Corresponding author: eevc2000@hotmail.com

The application of carbon fiber and fiberglass has diversified, due to its excellent mechanical, chemical and thermal properties [1,2]. The applications of carbon fibre and fiberglass range from the construction field, manufacturing of electrical elements, as reinforcement in concrete, electrical and thermal insulation, parts for automotive and aeronautical industry, etc.[3-5]. In this work we report the SEM and EDS of carbon fiber and fiberglass samples obtained by the Resin Transfer Molding (RTM) process at National Center for Aeronautical Technologies (CENTA, Querétaro, México).

For the production of the composite materials, 6 layers of fiber were placed with a bidirectional fabric array of 0 and $90^{\circ}$ inside a sheet-shaped aluminum mold, afterwards, the mold was closed applying a pressure of 1.5 tons and material was injected at a speed of $17 \mathrm{cc} / \mathrm{min}$ at $50{ }^{\circ} \mathrm{C}$. An amount of $292 \mathrm{~g}$ of resin and $93.5 \mathrm{~g}$ of hardener epolam 2015 were mixed. Once the mold was filled with an injection pressure of 70 psi for 120 minutes, the sheets were left inside the mold for curing for a period of 4.5 hours at a temperature of $60^{\circ} \mathrm{C}$, once dried, the sheets obtained were removed.

Figure 1 shows the SEM of the cross section of the carbon fiber and fiberglass specimens, with a zoom corresponding to one of the orientation of the carbon and glass fibers, respectively. Figure 2 shows the micrographs that correspond to the orientation of the fibers within the polymer matrix. Figure 3 shows the chemical composition of the longitudinally oriented fibers and the polymer matrix formed by the resin and the hardener, verifying the presence of the elements corresponding to the carbon fiber and the fiberglass.

References:

[1] P Bhatt and A Goe, Mater Sci Res India 14 (2017), p. 52.

[2] W Chen et al., Constr Build Mater 143 (2017), p. 247.

[3] F Meng, J McKechnie and SJ Pickering, Compos Part A Appl Sci Manuf 109 (2018); p. 207.

[4] D Falliano et al., Compos Struct 209 (2019), p. 45.

[5] V Le Louët et al., Int J Heat Mass Transf 112 (2017), p. 882. 

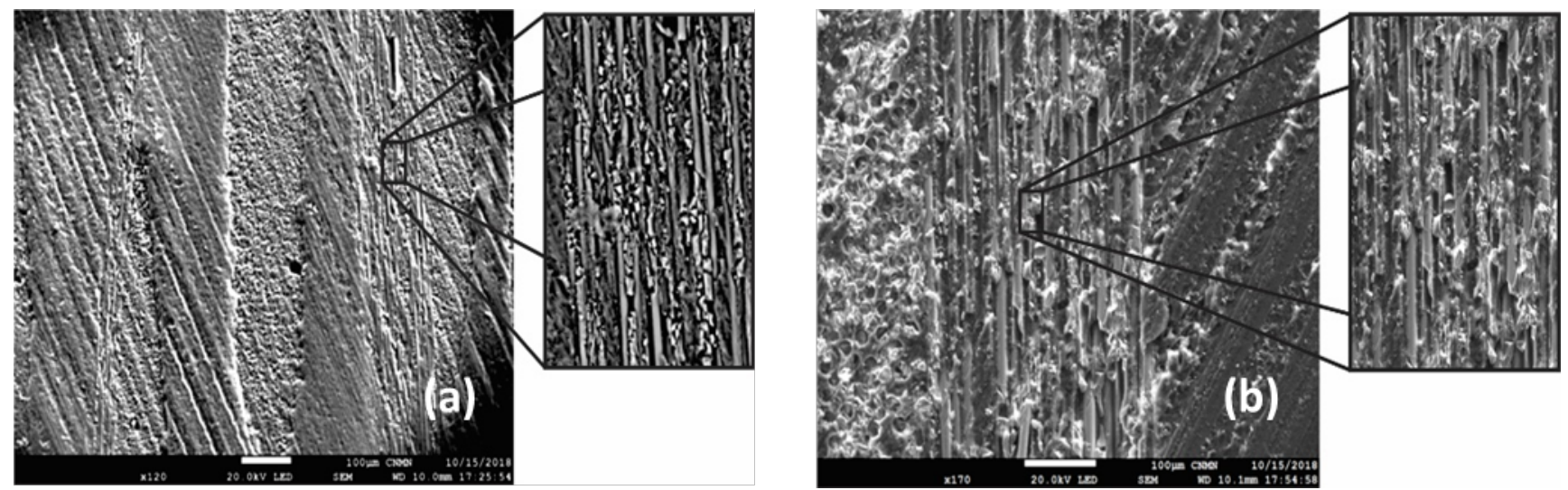

Figure 1. SEM micrograph of the cross section. (a) Carbon fiber, (b) fiberglass
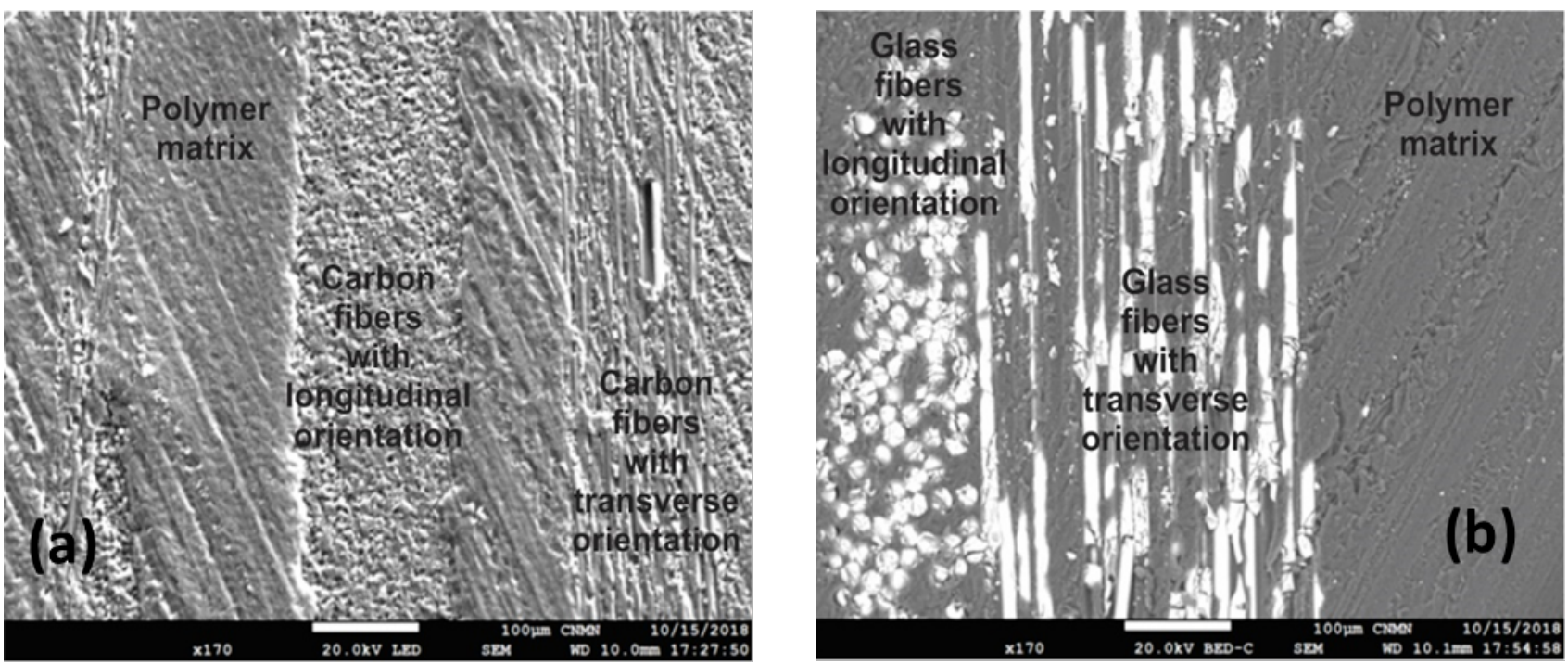

Figure 2. SEM micrograph of the fiber orientation. (a) Carbon fiber, (b) fiberglass

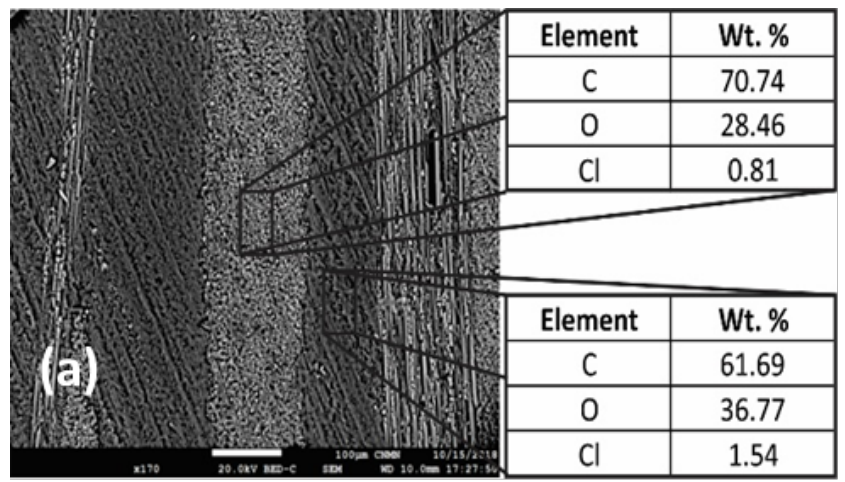

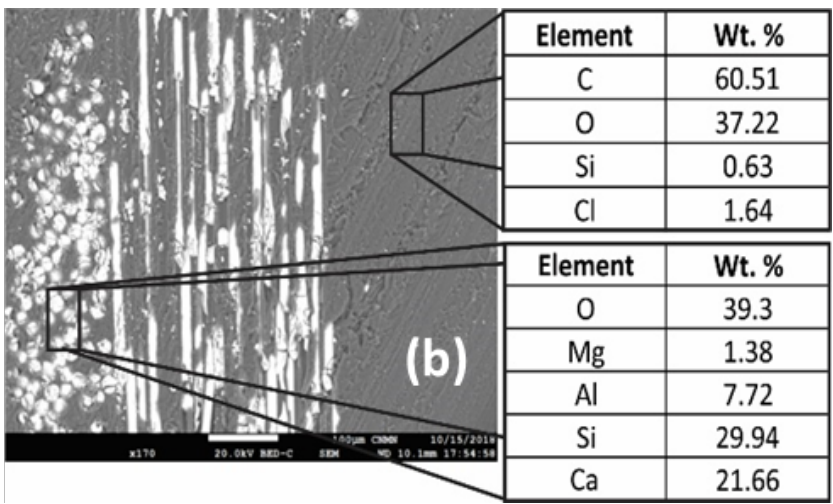

Figure 3. Chemical composition by EDS of the cross section. (a) Carbon fiber, (b) fiberglass 